\title{
AMPLIACIÓN DE LOS HORIZONTES CRONOTÓPICOS DE LA NOVELA GÓTICA
}

\author{
Miriam LÓPEZ SANTOS \\ Universidad de León \\ mlops@unileon.es
}

Resumen: Sistematización, desde el punto de vista de la teoría literaria de Mijail Bajtín, de las características que definen el cronotopo de la novela gótica. Valoración de las coordenadas en relación con el cambio de mentalidad que supuso la Ilustración.

Abstract: Systematization of the characteristics that define the gothic novel's chronotope from the viewpoint of Mijail Bajtín's literary theory. Valuation of the coordinates in relation to the mentality change that involved the Age of the Enlightment.

Palabras clave: Cronotopo. Novela gótica. Literatura fantástica. Terror. Estética de lo sublime.

Key Words: Chronotope. Gothic novel. Fantastic literature. Terror. Sublime aesthetics. 
La novela gótica fue relegada al cajón de la subliteratura ya desde el momento de su nacimiento, en la antesala misma del siglo XVIII y a la sombra de la purificadora y triunfante Ilustración. Junto a ella surgieron la novela histórica y la novela sentimental, que contribuyeron a asentar el género gótico, gracias a un más que aceptable engranaje de componentes narratológicos. La novela gótica, precisamente para distanciarse de esas otras dos modalidades, resaltó e incidió sobremanera en el componente espacial y temporal, entendido como un todo inteligible y concreto, destinado a convertirse en emblema indiscutible de esta nueva literatura.

El formalista ruso Mijail Bajtín sería el primero en teorizar esta cuestión, si bien es cierto que contemporáneos como Coleridge o Kant ya habían apreciado con anterioridad, en el caso de las novelas de El Siglo de las Luces, una relación aún más estrecha que en sus predecesoras, entre la coordenada espacial y la temporal. Sin embargo, no sería hasta la publicación de la obra Teoría y estética de la novela, por el propio Bajtín (1975), cuando esta intuición queda definitivamente sistematizada. Su término cronotopo ${ }^{1}$ supuso un acercamiento novedoso a la interpretación y consideración de ambos elementos narratológicos. Desde esta perspectiva, las coordenadas espaciotemporales de una novela no podrían ni deberían ser estudiadas de manera autónoma, como departamentos estancos entre los que no existen relaciones, pues el espacio en estado puro no existe, precisa del tiempo para desarrollarse y materializarse en la obra literaria.

Al demostrar una afinidad, una fuerte dependencia entre las mismas, este autor pretende explicar las fronteras entre géneros y el nacimiento de los nuevos subgéneros literarios, pues «el género y sus variantes se determinan precisamente por el cronotopo» (Bajtín, 1989: 238). Su reflexión abriría el camino a la consideración de un subgénero: la novela gótica, nacida de la especial conexión entre ambas coordenadas, es decir, de la conjunción de un tiempo histórico pasado y del castillo como el nuevo espacio en el que transcurren los acontecimientos de la narración.

No debemos olvidar, más allá de esta unión indisoluble, que el tiempo y el espacio que nos presentan estas novelas son radicalmente opuestos a los que podemos hallar en los textos considerados canónicos. Las coordenadas

1 Bajtín (1989: 238) define cronotopo como «la unión de los elementos espaciales y temporales en un todo inteligible y concreto. El tiempo se condensa aquí, se comprime, se convierte en visible desde el punto de vista artístico; y el espacio, a su vez, se intensifica, penetra en el movimiento del tiempo, del argumento, de la historia. Los elementos del tiempo se revelan en el espacio y el espacio es entendido y medido a través del tiempo». 
espacio-temporales en las narraciones góticas tienden al fragmento y a la deformación, encontrándonos con las repeticiones obsesivas de un tiempo circular, las interferencias de tiempos paralelos o las distorsiones de un tiempo que se acelera o se detiene; de la misma manera, el espacio tampoco es constante, identificándose lugares diferentes o, por el contrario, abstrayéndose estos en un espacio intangible, casi psicológico. Se perdía, pues, esta novela en caminos laterales y acababa, así, para teóricos y críticos de este siglo XVIII, por infringir la ley de la claridad, relacionada directamente con el hasta entonces irrefutable principio aristotélico de verosimilitud.

Sin embargo, nosotros, siguiendo a estudiosos como Julia Barella, entendemos que la verosimilitud ${ }^{2}$ de los hechos narrados está dentro de la categoría de la lógica y coherencia interna del relato (Barella, 1994: 14), sea cual sea el género literario que se trate, y depende en mayor medida de esta categoría más que de la relación que se establezca con el mundo referido. Dentro de la categoría de la literatura gótica, como paralela a la literatura fantástica, serán verosímiles las reacciones y acontecimientos que se desarrollen en el marco de estas distorsionadas coordenadas espacio-temporales. Lo entiende de la misma manera Ana María Morales cuando afirma que en este tipo de textos nos enfrentamos a una verdad ilegal, pero fáctica, que resulta presumiblemente insólita, pero real de acuerdo con el resto del sistema del relato (Morales, 2004: 34). Así pues, como dijéramos anteriormente, lo verosímil no tiene por qué oponerse a la estructura gótica, sino que se entiende como un criterio más amplio que depende del género literario que estemos estudiando. Y en esta concepción más amplia deberían tenerse presentes los factores culturales, pues, como señalara José Ángel Vargas, «el concepto verosímil está sometido a un relativismo cultural, se circunscribe a un área geográfica, histórica y cultural bien definida» (Vargas Vargas, 1993: 14).

Modificado el planteamiento de este principio, las leyes de la percepción sufren continuas perturbaciones que acaban por quebrar las expectativas racionales de los lectores, empujando a estos hacia laberintos inusuales, territorios lejanos e inhóspitos, donde el exotismo, no solo generaba estremecimiento hacia lo desconocido, sino que se convertía en fuente continua de provocación.

Este sometimiento de la novela a un espacio y a un tiempo del todo ilógico, fuera del control de la propia estructura del relato y de la comprensión

${ }^{2}$ En relación con el problema de la verosimilitud fantástica, véase Jirí Šrámek, «La vraisemblance dans le récit fantastique». 
de los lectores, trata de constatar el desconcierto, el desamparo de los protagonistas, quienes no perciben más que el desacuerdo de los hechos con relación a un patrón teórico, la norma considerada como aceptable, como real.

\section{EL ESPACIO NARRATIVO}

El espacio, a pesar de la complejidad y ambigüedad de su noción, es un componente integrante e imprescindible de la construcción narrativa. El espacio, como sabemos, es un elemento estructural cuya finalidad no se reduce a ser el ámbito en el que se desarrolla la acción, sino que ayuda a configurar los rasgos psicológicos de los personajes e influye en sus conductas, llegando a erigirse, en algunos casos, en el verdadero eje determinante y definitorio de la obra literaria ${ }^{3}$. Este es el caso del relato gótico al que el espacio ha servido de base constitutiva. La descripción del espacio en estas narraciones adquiere una importancia fundamental y si bien es cierto que se define por su relación con el resto de integrantes de la obra, sin este elemento espacial perdería no sólo la verosimilitud y el ensamblaje de la microestuctura (Garrido Domínguez, 1993: 216), sino también gran parte de sus significaciones primeras. Dada su complejidad y trascendencia hemos optado por establecer en el seno del espacio, con el propósito de lograr un estudio completo del mismo, una serie de consideraciones que procederemos a continuación a detallar.

\subsection{Funciones}

Con la llegada de la Ilustración y como consecuencia de la misma, el género narrativo comenzó a sentar las bases de lo que más tarde habría de lla-

\footnotetext{
${ }^{3}$ Han sido muchos los críticos que han reseñado la esencialidad del espacio en el seno de la obra literaria. Natalia Álvarez (2002: 36) trae a colación, por su claridad y acierto, las afirmaciones que Darío Villanueva (1989: 42) estableció para demostrar el papel preponderante del espacio en la ficción, en las que señala que «la situación narrativa implica necesariamente, si bien en diferente cuantía según los casos, uno o varios lugares, cuya presencia en el texto autentifica, da veracidad al relato, y sitúa a los personajes, cuando no proporciona interesantes efectos simbólicos o se erige en verdadero protagonista, como ocurre en las novelas de viaje o en las llamadas "novelas de ciudad"; en resumen, en la novela la funcionalidad de estas coordenadas es doble: semántica y compositiva; pues como ha demostrado María del Carmen Bobes Naves (1985: 207), en ella se utiliza "el espacio como un signo que remite a la situación de los personajes, a sus modos de pensar y de conducirse, y además como un elemento estructural que permite la construcción de la sintaxis narrativa"».
} 
marse «el siglo de la novela». En este proceso de eclosión asumió rasgos y funciones hasta entonces impensables y aunque resulta constatable que otros componentes narrativos apenas consiguieron desprenderse de «males» pasados, no le sucedió lo mismo al componente espacial que dejó de verse como un mero elemento ornamental. En un intento de aprovechar la enorme riqueza narratológica, los escritores góticos comenzaron a dotar al espacio de nuevas funciones.

Sería el filósofo Edmund Burke el encargado de determinar y fijar, desde el punto de vista estético, las propiedades del mismo, estableciendo una distancia más que considerable con la tradición anterior ${ }^{4}$. Habla de un espacio determinado por la intersección de una serie de elementos imprescindibles, sin los cuales no se podría caracterizar cierto texto como perteneciente a este género. Inmensidad, infinidad, oscuridad, soledad o brusquedad como elementos constitutivos de lo sublime, determinan el espacio de estas novelas, convirtiéndolo, más que en espacio referencial, en lo que podríamos denominar espacio estético ${ }^{5}$. Los narradores góticos no solo pretenden facilitar al lector la labor de percepción de los acontecimientos de la historia, sino que también intentan hacerles partícipes de la magnificencia y sublimidad del mismo. Kant, también en esta misma línea, lo calificó de espacio terrorífico, repleto de lóbregas encinas, alamedas sombrías y secretas, tétricas sombras, luces tenebrosas, y todo envuelto en una oscuridad espeluznante, fría, casi apocalíptica. Una escenografía - antesala de lo que años más tarde sería el paisaje romántico - extrema, cercana a la teatralidad, la misma boca del infierno ${ }^{6}$.

En el ensayo titulado The Supernatural in Poetry, Ann Radcliffe enumeró también con bastante detalle los lugares o paisajes que debieran con-

${ }^{4}$ Natalia Álvarez Méndez (2002: 48) constata cómo Jovita Boves (1992: 321) advierte en relación a este hecho que «la significación del tiempo y del espacio, en cada época, está en relación con el valor que les da la filosofía. Su concepto ha evolucionado a lo largo de la historia con una intensificación progresiva en su valor referencial que no es unívoco en cada obra, pero que se asocia en ella a un uso específico e intencionado, formando "sistemas sémicos" propios».

${ }^{5}$ Recuerda Antonio Garrido Domínguez (1993: 215-216) que la función referencial tiene que ver con la presentación ante el lector de la acción narrativa como una realidad concreta y perceptible.

${ }^{6}$ En la escenografía gótica se percibe, con claridad, la influencia de los grabados del pintor Giovanni Battista Piranesi. Nos encontramos con el mismo mundo arquitectónico carente de puntos de referencia del castillo gótico. Praz llega a afirmar, incluso, que habría sido la visión de una de sus cárceles, en la que aparece un trofeo coronado por un monumental yelmo emplumado que pende amenazador sobre los empequeñecidos hombres abajo, lo que inspiró a Walpole el sueño que concibió su novela (Praz, 1970: 17). Nacido en 1720, Piranesi pasó gran parte de su vida dibujando las ruinas de Roma, que siempre le parecieron aterradoras y opresivas. El efecto tenebroso y terrorífico de sus estampas viene dado por un espacio gigantesco que contrasta con la escala de figuras; estas cárceles son verdaderas ciudades, en las que los seres humanos parecen acosados por la inquietud y la violencia. Se trata de un espacio laberíntico, construido por grandes masas de piedra, con multitud de escalinatas y pasarelas que se entrecruzan. 
vertirse en motivo literario dentro de la novela gótica, apoyándose en figuras de la talla de Shakespeare y Milton, que aprovecharon al máximo los recursos que este les ofrecía. La novedad de su afirmación reside, sin embargo, en que considera que solo los grandes escritores poseían la virtud de dibujar en sus novelas paisajes capaces de alcanzar y provocar este efecto de lo sublime:

When they (Shakespeare y Milton) were acted upon by the illusions of tose great masters of the imagination, at whose so potent bidding, the passions have been awakened from their sep, and by whose magic a crowded Theatre has been changed to a lonely shore, to a witch's cave, to an enchanted island, to a murderer's castle, to ramparts of an usurper, to the battle, to the midnight carousal of the camp or the tavern, to every various scene of the living world (Clery, 2000: 196).

Precisamente fue esta, de entre todos los escritores góticos, la que mostró en sus novelas un mayor interés por el paisaje; un paisaje «encantadoramente pictórico, de trazo amplio, sin detenerse nunca en los detalles de primer término» (Lovecraft, 1989: 24) ${ }^{7}$, al que otorgó en todos sus relatos un papel preponderante, que enfatiza su carácter autónomo dentro de la novela y sus abrumadores efectos sobre los personajes que lo contemplan. Así describe el narrador la primera impresión de los Apeninos en Los misterios de Udolfo como algo más que un marco físico: el escenario en el que está representada la tensión, a menudo dramática, entre la sublimidad de la naturaleza y la limitación del espíritu humano:

Estaba rodeado por montañas cuyas pendientes parecían ser inaccesibles. Hacia el oeste se abría el paisaje que exhibía a los Apeninos en sus más oscuros horrores, y la larga perspectiva de las cumbres, elevándose una sobre otra, mostraba una profunda imagen de grandeza que Emily no había contemplado nunca. [...] Silencio, solemnidad y sublimidad parecían ser los soberanos del paisaje, desafiando a todos los que se atrevieran a invadir su reino solitario (Radcliffe, 2001: 398-399).

No es esta, sin embargo, la única función que cumple el complejo espacio en el marco de las novelas góticas. Lo gótico, por otra parte, condensaba en rigor una representación difusa de lo que se suponía había sido el

7 A este respecto Aileen Dever (2007: 61) sostiene que, aunque la obra de Radcliffe podría resultar algo pesada y previsible, hay que reconocer el valor de su técnica en la creación de atmósferas peculiares y en el dibujo de paisajes, claros precursores de la atmósfera romántica. 
pasado medieval inglés de aquella ya vieja y anacrónica aristocracia ${ }^{8}$. Por ello, pasará a desempeñar, además de la reseñada función estética, una clara función social ${ }^{9}$. Viene a representar todas las angustias y opresiones de una sociedad, de una clase social, en constante transformación y en evidente decadencia, cuya luz no era tan fuerte ni tan purificadora de conciencias como sus impulsores intentaban hacer creer. El espacio histórico se transforma así en un lugar esencial, más protagonista que telón de fondo o marco de la escena de estas novelas y más propulsor de la acción que soporte de la misma, dado que todos los conceptos ${ }^{10}$, ideas, obsesiones y sentimientos de esta clase aristócrata se expresan a través de él, adquiriendo de este modo el sentido específico que tratan de trasmitir. En Los misterios de Udolfo observamos la amarga opresión en la que se siente inmersa la protagonista, al comprobar que se encuentra sola en el mundo a merced de las disposiciones de un tirano:

Emily, cuando miró las cumbres nevadas de los Apeninos, ascendiendo en la distancia. Pensó en el castillo de Montoni y sintió el terror de que pudiera ser confinada allí con el propósito de forzar su obediencia; pero su temor desapareció al considerar que estaba tan en su poder en Venecia como en cualquier otra parte (Radcliffe, 2001: 379).

En el intento de plasmar toda aquella opresión emplazaron la mayor parte de las novelas en ambientes latinos, en territorios a orillas del Mediterráneo, al condensar estos, en esencia, todos los miedos y temores de la sociedad aristocrática anglosajona, porque vieron en aquellos países no la luz grecolatina, sino la oscura e inquietante sombra de un pasado tenebroso. Ita-

${ }^{8}$ La novela gótica nació en la Inglaterra del siglo XVIII, único país donde un grupo social que no formaba parte de la burguesía tomó conciencia del nuevo mundo que se abría paso y del viejo mundo, de aquel viejo orden que comenzaba a desvanecerse. El grupo aristocrático o noble sufría «una insalvable decadencia y necesitaba purgarse con artística catarsis de una revolución burguesa que le arrebataba el universo» (Ferreras, 1973: 245).

${ }^{9}$ Estébanez Calderón (1999: 362) en su Diccionario de términos literarios desarrolla con varios ejemplos lo que podemos denominar «espacio social»: «El espacio es, no solo el ámbito de desarrollo de la acción, sino, también, el condicionante de determinados rasgos sicológicos de los personajes [...], así como de ciertos modelos de conducta y de la propia incardinación del personaje en el estrato social correspondiente».

${ }^{10}$ Ramos Gómez (1988: 145) defiende esta misma idea. Considera que el espacio de las novelas góticas no pertenece a la realidad cotidiana, sino a la soñada: «No se mide en kilómetros, sino en angustias y alegrías: de la misma manera que los jardines románticos se componían de rincones que significaban distintos estados de ánimo, el relato de trasgresión va pasando de unos lugares a otros, con las repercusiones psicológicas pertinentes. Mansiones, cavernas, pasillos, bosques, castillos, torres, conventos o subterráneos, antes de ser simples decorados donde la acción tiene lugar, la determinan de alguna manera, señalan la colaboración de lo que allí va a acontecer». 
lia y España, se convertirán así, dentro de esta imaginería, en lugares de acción góticos por excelencia. De esta manera, Lewis sitúa su historia en España, concretamente en Madrid, un mítico Madrid gótico, decadente e hipócrita, «una ciudad donde la superstición reina con despótico rigor» (Lewis, 2003: 115).

\subsection{La imaginería gótica. El castillo y el convento: espacio de la opresión / espacio de la protección ${ }^{11}$}

El espacio de las novelas góticas presenta, asimismo, la particularidad de ser siempre doble: el espacio de la opresión, por un lado, en el que el personaje sufre una gran ansiedad e inquietud ante el medio hostil que le rodea, y el espacio de la protección, por otro, que genera sensaciones más satisfactorias y placenteras y en el que los mismos personajes ven paliadas todas sus ansiedades y angustias. La imaginería gótica reconoció el valor de este artificio literario y tomó el castillo y el convento ${ }^{12}$, signos y emblemas más representativos del entonces remoto y glorioso pasado medieval, y los dotó de preponderancia sobre el resto de espacios narrativos, asignándoles respectivamente estos valores reseñados.

Comparten ambos, el castillo y el convento, la particularidad de constituirse como espacios cerrados, casi herméticamente, y de los que, por lo mismo, la huida se antoja del todo imposible. Además, a pesar de presentarse ante el lector como mundos aparentemente finitos, se descubren en el relato como arquitectura inagotable, destacando sobremanera sus enormes posibilidades de versatilidad. En efecto, estos espacios no solo no están predispuestos de antemano, sino que pueden llegar a ser cambiantes a lo largo de todo el relato, complicando más la estructura e incidiendo en las penalidades a las que se ven sometidos los protagonistas. Los límites no son fijos ni evidentes, transformándose de pronto ante el horror de los personajes. Aunque bien es cierto que el lector ya sabe de antemano que ciertos lugares, dentro de los mismos, no presagian nada bueno, porque los reconoce como escena-

11 Natalia Álvarez, en su interesante trabajo Espacios narrativos (2002) y en «Hacia una teoría del signo espacial en la ficción narrativa contemporánea» (2003), establece una serie de tipologías del espacio entre las que se encuentran algunas a las que hemos hecho referencia en nuestro estudio.

${ }^{12}$ Como en Inglaterra no había conventos, la idea que de ellos se tenía oscilaba entre la discreta parodia del Padre Isla en Historia del famoso predicador fray Gerundio de Campazas, alias Zotes (1758/1768) y las extravagancias de los franceses Baculard d'Arnaud y Dubois-Fontenelle. Como señala Molina Foix (2003: 23), antes de la aparición de las primeras novelas góticas ya existía en Inglaterra un género autónomo que tenía por protagonistas a monjas enclaustradas, casi siempre indecentes. 
rio de sus miedos nocturnos, estos serán, entre otros, los subterráneos, las habitaciones secretas, los cementerios y las criptas.

\subsubsection{El castillo gótico}

En estrecha relación con la obsesión, ya señalada, por el pasado que comenzó a proliferar en las últimas décadas del siglo XVIII, debemos situar la obsesión de esta literatura por el espacio cerrado del castillo ${ }^{13}$. El castillo «gangrena en el costado del Iluminismo» (Negroni, 1999: 182), se caracterizaba por estar casi siempre en ruinas y en medio de un paisaje desolado y yermo, no domesticado y, por lo tanto, sublimemente incomprensible. Udolfo, como todo castillo gótico, desde que Walpole recuperara para la posteridad Otranto, representa perfectamente este espacio. Los misterios de Udolfo de Ann Radcliffe transcurre en un castillo perdido y abandonado de los Apeninos, rígido por fuera, tétrico e inestable por dentro. Y así lo observa la propia protagonista, Emily, a través de la voz del narrador:

Aunque estaba iluminado por la puesta de sol, la grandeza gótica de su arquitectura y sus muros de piedra gris oscura, le daban un aspecto sublime y sombrío. Según miraba la luz se desvanecía en sus muros, dejando un tono púrpura, que se hizo cada vez más oscuro con el fino vapor que despedía la montaña, mientras las almenas seguían diciendo de su esplendor. De ellas también desaparecieron los rayos y todo el edificio se vio envuelto en la sombra solemne de la tarde. Silencio solemnidad y sublimidad parecían ser los soberanos del paisaje desafiando a todos los que se atrevieran a invadir su reino solitario. Según se oscurecía el crepúsculo, su silueta se hizo más tenebrosa [...] La extensión y oscuridad de aquellos altos muros despertaron

${ }^{13}$ El mismo iniciador del género, Horace Walpole, habiendo soñado su propio castillo medieval, se retiró de la actividad política, compró unos terrenos a orillas del Támesis, en el área de Strawberry Hill, a menos de treinta millas al sur de Londres, y durante años no hizo más que sacrificar todo aquello de lo que disponía en pro de un sueño obsesivo que él mismo no terminaba de soñar y cuyas reglas inexorablemente se le escapaban. Acabado ya, vino a demostrar que la imaginación se revela casi siempre como una forma de angustia (como dijera en su día Freud); y de su castillo soñado nació toda la escenografía que ya nunca habría de abandonar el género: estancias oscuras y claustrofóbicas, chimeneas inspiradas en las tumbas de las grandes catedrales, ventanas en forma de rosetas, paredes de seda de damasco plagadas de nichos, techos tapizados en terciopelo escarlata, pequeñas criptas donde reposaban estatuas o armaduras de caballeros andantes, etc. Los avatares de la construcción, así como el afiebrado proceso de escritura de la novela, que tuvo lugar en tres meses, están descritos en Wyndham Ketton-Cremer, Horace Walpole. A biografhy (Londres: Longmans, Gren and Co., 1940, 211-219). También William Beckford, en la misma línea, mandó construir una morada negra, ya desaparecida, en las proximidades de Bath que serviría, al propio tiempo, de inspiración a su novela Vathek. Fonthill Abbey, una abadía gótico-sarracena, fue, en su momento, el edificio más sobresaliente y esplendoroso del gótico inglés. 
imágenes terroríficas en su mente [...] pero la oscuridad reinante no le permitió distinguir mucho más de esa parte de su trazado, salvo saber que era grande, viejo y triste (Radcliffe, 2001: 399).

Más que un decorado, no obstante, «era la evidencia de que no hay construcción que no lleve en sí misma el germen de la propia destrucción» (Molina Foix, 2003: 13). Se privilegia el castillo como exponente de determinados valores, dado que pretendía simbolizar la opulencia, la hegemonía y la superioridad de un poder feudal venido a menos, así como la opresión con que se sujetaba al súbdito, especialmente a la mujer y a los considerados inferiores ${ }^{14}$. Un entorno cerrado como epítome del aislamiento feudal y símbolo de la diferencia histórica entre el pasado imaginario y el presente de la narración, que se convertirá en marco idóneo para situar las tétricas y siniestras tramas góticas, pues, no olvidemos, que los castillos, y sobre todo los castillos en ruinas, solían, o al menos esto afirmaban multitud de comentarios supersticiosos, estar frecuentados por fantasmas.

El castillo representa, por lo mismo, el espacio del confinamiento. Aparece como prisión, como coacción de la libertad del protagonista (la mayor parte de las ocasiones femenino), lo que termina por configurarlo como una expresión metafórica ${ }^{15}$ de este. Nos encontramos entonces ante un espacio marcadamente opresor. Esta sensación de angustia se logra gracias a la capacidad semántica del espacio, cuyas coordenadas sirven de proyección de las relaciones y conductas de los personajes con sus consiguientes contenidos significativos ${ }^{16}$. La interrelación entre personaje y espacio llega a ser tan intensa que da lugar a una identificación sémica entre ambos componentes narratológicos, lo que entendemos puede constituir la llamada función «identificadora», acuñada por el teórico Cuesta $\mathrm{Abad}^{17}$. Y es por ello por lo que la crítica ha vinculado estrechamente el castillo gótico a las emociones y ex-

${ }^{14}$ En este sentido, señala María Negroni, en su ensayo La cripta de la literatura, que el castillo gótico como máximo significante de la angustia y del encierro será empleado posteriormente por Franz Kafka como eje constitutivo de su novela Das Schloss (1982). Aprovecha, entonces, la etimología alemana de la palabra «Schloss» como «cerradura», «encierro»y «bastión» o «castillo».

15 Fueron Wellek y Warren, como recuerda Garrido Domínguez (1993: 217), los primeros en apuntar la consideración del espacio como una metáfora o metonimia.

16 Bobes Naves (1983: 124-125) sostiene esta misma idea al analizar el caserón en el que vive Ana Ozores, protagonista de La Regenta: «un edificio viejo, pretencioso, amplio e incómodo. Ana se siente prisionera, aunque en un momento lo mira como refugio, [...] el valor metafórico de estos lugares en relación a los personajes es directo y llega en algunos casos a ser icónico, es decir, llega a reproducir físicamente algunos de los rasgos que caracterizan funcionalmente al personaje».

17 Cuesta Abad (1989: 478-479) resume las diferentes funciones que surgen de las conexiones existentes entre personaje y espacio. Las cita en su trabajo Natalia Álvarez Méndez (2002: 55): «la identificación: es la integración sémica del personaje en su espacio, las notas semánticas del personaje se 
periencias individuales de los personajes, «como dos caras de la misma moneda, por la que el tiempo anímico se transmuta en un espacio simbólico» (Amicola, 2002: 52). Es más, podría considerarse, incluso, como el lugar donde se expresan con claridad deslumbrante, como en una metáfora paranoica, las ansiedades y conflictos sociales de su época:

Las incertezas que provoca la aparición de la New Woman, las nuevas normativas en materia de propiedad, herencia y riqueza, los avances técnicos en un mundo que, no obstante estar iluminado por la razón y la gramática de la cronología (o precisamente por eso), ha perdido el sentido espiritual de la existencia (Negroni, 1999: 188-189).

De hecho, en esta misma línea, señala Julia Kristeva que el castillo se convierte en metáfora proyectada de una alucinación que nos coloca frente a los límites para expresar la abyección de sí (Kristeva, 1980: 58-59) ${ }^{18}$; es decir, una representación en piedra de los torturados y oscuros recovecos de la mente civilizada porque en su estructura podemos reconocer las criptas y sótanos del deseo reprimido, y las torres y campanarios de la neurosis.

Isabella, cautiva en el castillo de Manfredo, cree vivir en una prisión que la ahoga y de la que no ve escapatoria posible:

La dama, cuya decisión había dado paso al terror en el momento en que abandonó a Manfredo, continuaba su huida hacia la parte baja de la escalera principal. Alli se detuvo, sin saber a dónde dirigir sus pasos, ni cómo escapar de la impetuosidad del príncipe. Sabía que las puertas del castillo estaban cerradas y que había guardias en el patio (Walpole, 1982: 9).

A este espacio de la opresión contribuye la escalofriante y aterradora escenografía que se le supone y se le asigna; implicaría, para Lovecraft, una serie bien definida de elementos concretos para la escenificación del horror: «húmedos corredores, malsanas catacumbas y un sin número de leyendas y fantasmas estremecedores [...] luces extrañas, trampas húmedas, lámparas apagadas, manuscritos ocultos y mohosos, goznes chirriantes y tapices que se estremecen» (Lovecraft, 1989: 21-22). Dentro de este espacio esos pequeños

traducen en el espacio. La contrastiva: con discordancia entre personaje y ambiente. La coordinativa: el espacio es un lugar de encuentro y en otros casos de separación de personajes. La transformativa: como consecuencia de la movilidad o el estatismo espaciales a causa de la acción de los personajes. Espacio-trayectoria/espacio enclave».

18 Julia Kristeva seguía posiblemente a Freud al hacer esta afirmación. El gran maestro del psicoanálisis y sus continuadores equiparan la psique humana con una gran casa atormentada por el pasado, llena de recámaras oscuras, herméticas, que ocultan, en la mayoría de las ocasiones, un secreto sexual. 
elementos escenográficos adquieren una importancia determinante; desempeñarían la función de acentuar dentro de la estructura de la novela gótica «su carácter de rompecabezas, de calidoscopio, de juego de formas literarias y arquitectónicas que se superponen y transponen provocando que el orden y la unidad (factores que definían la novela Iluminista) dejen de ser los valores de referencia» (Molina Foix, 2003: 23). Es más, estos extraños decorados obsesivos y opresivos tienen una misteriosa vida propia, latente, pues, como apunta Maurice Levy, «il semble que ce soient les demeures gothiques, plus que les hommes qui les habitent, qui infligent souffrance et mort» (Levy, 1968: 270).

El espacio gótico, además de presentarse como una cárcel, adquiere rasgos de laberinto. Esconde una dimensión oculta, la mayoría de las veces subterránea; un mundo siempre caótico que adquiere forma de rompecabezas y donde los caminos o pasillos no conducen a ninguna parte, sino que están trazados para confundir y perder a todo aquel que los recorre. Porque, y así es fácilmente constatable, el laberinto, no lo olvidemos, es un espacio deformado que no se puede identificar; es una dirección que conduce a la pérdida; como en todo laberinto, el protagonista se encontrará, aquí y allá, con lugares de horror o cámaras de muerte, con un subterráneo, un calabozo o un cementerio de los que saldrá para llegar a otro lugar que resultará ser idéntico; un laberinto oscuro, eterno e infernal en el que pesan, paradójicamente y en consonancia con el resto del relato, más los pasillos, corredores y pasadizos subterráneos (a los que estos escritores reservan páginas de descripciones sumamente detalladas ${ }^{19}$ ), que las habitaciones, jardines o salones.

El castillo de Otranto, «de pavorosa antigüedad», aislado e inquietante, presenta en su interior, y concretamente en sus subterráneos, una disposición laberíntica que contribuye a confundir a los personajes y aumentar la sensación de terror desmedido. Isabella, armada de valor, se interna en el subterráneo del castillo para huir de Manfredo:

La parte baja del castillo estaba recorrida por varios claustros inclinados, y no resultaba fácil para alguien tan ansioso dar con la puerta que se abría a la caverna. Un terrible silencio reinaba en aquellas regiones subterráneas, salvo, de vez en cuando, algunas corrientes de aire que golpeaban las puertas que ella había franqueado, y cuyos goznes, al relinchar, proyectaban su eco por aquel largo laberinto de oscuridad. Cada murmullo le producía un terror nuevo, pero aún temía más escuchar la voz airada de Manfredo ur-

19 Especialmente espeluznante es la descripción que de la cripta del convento de Santa Clara nos ofrece uno de los personajes de El Monje: «deprimente lugar en medio de la noche, rodeada de los cadáveres putrefactos de mis compañeras muertas, esperando a cada instante ser despedazada por los fantasmas que vagan en torno a mí, lamentándose, gimiendo y quejándose» (Lewis, 2003: 467). 
giendo a sus criados a perseguirla. Avanzaba sin hacer ruido, en la medida que su impaciencia se lo permitían, aunque se detenía a menudo y aguzaba el oído para saber si la seguían (Walpole, 1982: 9).

El castillo, como venimos observando, aparece como centro de la mayor parte de las novelas góticas, como hilo conductor de los destinos y designios de los personajes que lo habitan y como responsable de gran parte de sus miedos más profundos. Resulta interesante destacar, para ahondar más si cabe en su trascendencia, el hecho de que gran parte de las novelas calificadas como góticas llevasen por título el espacio donde se desarrollan. Este es el caso de la iniciadora del género, El castillo de Otranto. Destaca este título, sobre todo, si se establece una contraposición con el resto de obras calificadas como «novelas» que ya empezaban a forjarse en diversos estados del viejo continente y que optan por subrayar el nombre de sus protagonistas ${ }^{20}$.

Todas las aseveraciones que hemos realizado contribuyen a justificar el peso en la novela de este componente, que pasa en determinadas situaciones a ser un actante más de la trama, llegando incluso a erigirse como verdadero protagonista en los momentos de mayor tensión dramática. La repetición constante de este motivo espacial y la acción que tiene lugar en él se convertirán en un cliché, en un estereotipo que pasará a formar parte de toda la imaginería romántica posterior, cualquier tipo de escena que implique el horror difícilmente podrá concebirse sin la presencia de este elemento literario.

\subsubsection{El convento}

El convento, en sus más diversas variedades de abadía, monasterio o hermandad, aparece siempre como lugar obligado en la creación de todo espacio gótico. Desempeña el papel de escenario feliz, englobando todos los valores positivos y aportando auxilio, amparo y seguridad. No adquiere, sin embargo, un papel protagonista; simplemente viene a representar lo que llamamos el espacio de la protección ${ }^{21}$; a este espacio es al que se encomiendan los diversos personajes que huyen de las perversidades del prota-

${ }^{20}$ En las postrimerías del siglo XVIII son abundantes las muestras de novelas que llevan por título el nombre del protagonista o de alguno de sus personajes. Algunos ejemplos ilustrativos serían Samuel Richardson (1689-1761) con Pamela o La Virtud recompensada, Henry Fielding (1707-1754) con Tom Jones (1749), o cualquiera de la abundante producción de Walter Scott como Ivanhoe (1819), Rob Roy (1818) o El pirata (1822).

${ }^{21}$ Gastón Bachelard (1965: 7-32) habla de topofilia para referirse a estos lugares de la felicidad y el sosiego. 
gonista. Su presencia en la novela se justifica como contrapunto a las fuerzas malignas encarnadas en el castillo, potenciando así las tonalidades negativas de este espacio de la opresión.

Las protagonistas de las novelas góticas, agraviadas y perseguidas por sus correspondientes villanos, buscan refugio en los conventos o iglesias cercanas:

Pero ¡Dónde ocultarse! ¡Cómo escapar a la persecución a que infaliblemente la sometería por todo el castillo! Mientras tales pensamientos cruzaban con rapidez su mente, recordó un pasadizo subterráneo que conducía desde las bóvedas del castillo a la iglesia de San Nicolás. Podía alcanzar el altar antes de ser detenida, pues sabía que ni siquiera la violencia de Manfredo osaría profanar la santidad del lugar. Y si no se le ofrecía otro medio para liberarse, estaba decidida a encerrarse para siempre entre las vírgenes consagradas, cuyo convento se hallaba contiguo a la catedral (Walpole, 1982: 9).

Sin embargo seguía abierto en Francia un asilo para ella seguro y apropiado. Sabría que podría habitar en el convento, en el que ya había experimentado y recibido tantas amabilidades y que había afectado solemnemente su corazón, puesto que en él estaban los restos de su difunto padre. Allí podría vivir segura y tranquila (Radcliffe, 2001: 360).

El castillo como espacio del confinamiento, primordial y prácticamente indispensable para poder hablar propiamente de novela gótica, amplía sus horizontes de la mano del reformador del género, Lewis. El renovado villano de Lewis, ahora en el papel de monje, precisa, pese a lo señalado, un evidente cambio de escenario. El convento, junto con el castillo encantado y en ruinas, pasará a convertirse, de la mano de este escritor, en un nuevo espacio gótico opresor donde desarrollar estas terroríficas tramas. Con este juego literario de gran valor artístico desaparecerá casi por completo el espacio de la protección, quedando reducido a límites mínimos y confiriendo a la novela una sensación opresora cercana a la asfixia. Nos encontramos ante un auténtico mundo de pesadilla donde no hay escapatoria posible ni lugar del que no pueda apoderarse el maligno. Ya no existe construcción capaz de dar cobijo, sino que ahora todas aprisionan. La influencia de este «mundo» exterior en el «mundo» interior ${ }^{22}$ de los actantes genera, en definitiva, un espacio cerrado, un universo que se contrae y adquiere dimensiones ínfimas hasta adaptarse a la realidad y al entorno inmediato de los mismos.

22 Aileen Dever (2007: 70-71) prefiere, por ello, hablar de un cosmos individual, más que de un universo a escala humana, en el que los acontecimientos, que suceden más allá de los del cerrado entorno que envuelve al protagonista, pertenecen a otra esfera diferente y, en consecuencia, pueden y deben ser ignorados. Eugenio de Nora para referirse a estos ambientes emplea el concepto de espacios conexos. 
En el convento de los Capuchinos, los personajes sufren el encierro, la soledad y el desasosiego, ya que se encuentran encerrados y oprimidos por ese espacio que los aprisiona y por este ambiente asfixiante que puede apreciarse a cada página una vez que comienza a desarrollarse la trama en sí. Antonia, recluida en los calabozos de un convento que ya no es fuente de consuelo, se lamenta de su situación:

Con los ojos descorazonados, examiné aquel escenario de sufrimiento y, al pensar que estaba condenada a pasar en él el resto de mis días, me partió el corazón la más amarga de las angustias. ¡De qué manera tan diferente habíanme enseñado en otro tiempo a encarnar el futuro! [...] todo lo había perdido ahora: amigos, consuelo, compañía, felicidad. ;En un instante me privaron de todo! muerta para el mundo, muerta para el placer, no vivía más que para el sufrimiento [...] Cuando echaba una ojeada por mi prisión aterrada, cuando me estremecía por el cortante viento que bramaba en mi celda subterránea, parecíame el cambio tan brutal, tan brusco, que dudaba de que fuese real (Lewis, 2003: 512).

Otra realidad a la que nos enfrentamos al contemplar el espacio y que no debemos en ningún caso pasar por alto es el silencio como rasgo caracterizador del escenario narrativo, sea este el del castillo o el del convento. Frente a lo esperable, el silencio en el espacio gótico tiene una significación determinada y contribuye a enriquecer la lectura, añadiendo información extra, necesaria para rellenar «vacíos» y comprender el desarrollo de la trama. Este espacio del silencio, caracteriza toda la atmósfera y genera una sensación de desasosiego que aumenta el misterio y aviva los miedos y terrores ya presentes en los personajes. Es lo que sucede en Los misterios de Udolfo, cuando la protagonista se aventura a descubrir por ella mismas las estancias prohibidas del castillo:

Con una luz y pasos rápidos cruzó las largas galerías, mientras los débiles rayos de la lámpara que llevaba sólo le mostraban lo tenebroso del ambiente, y el viento amenazaba con apagarla. El tremendo silencio que reinaba en aquella parte del castillo la atemorizó y de cuando en cuando le llegaron las risas de un punto remoto del edificio, donde los criados estaban reunidos, pero pronto desaparecieron quedando sólo aquel silencio casi irrespirable (Radcliffe, 2001: 443).

Similar efecto tiene en las novelas el llamado espacio de la noche que se opondría al espacio del día. Frente a la claridad del día, la noche distorsiona la geografía que conocemos, los límites y los objetos se alternan de manera 
amenazante y estas transformaciones misteriosas contribuyen a intensificar la sensación de terror en los personajes. Percibimos la contraposición del espacio del día frente al de la noche en cada pasaje de las novelas góticas. En Emily, lo miedos dormidos durante el día, afloran con la proximidad de la noche:

Temblaba al mirar en la oscuridad de su espaciosa cámara y temió algo desconocido. Un estado de ánimo en el que habría llamado a Annette, la sirvienta de su tía, si sus miedos le hubieran permitido levantarse de la silla y cruzar la habitación (Radcliffe, 2001: 389).

La luz del día disipó de la mente de Emily las tinieblas de la superstición (Radcliffe, 2001: 423).

En suma, nos encontramos ante un espacio sumamente complejo, primordial y determinante; la misma razón de ser de las novelas góticas.

\section{EL TIEMPO NARRATIVO}

El tiempo externo de la novela gótica es siempre pasado, remoto y oscuro; en la mayoría de las ocasiones un pasado medieval que, por lo general, nunca aparece determinado con precisión. No olvidemos que en estos períodos de la historia abundaban las supersticiones y ante cualquier hecho aparentemente extraño se recurría a influencias de seres sobrenaturales, a la magia, la brujería o el demonio. Esta época, entonces, no puede ser más propicia para el desarrollo de este tipo de tramas.

Así, el relato de los acontecimientos en El Monje y en El castillo de Otranto no deja lugar a la duda de que el narrador sitúa la acción en el período medieval. No obstante, la fecha exacta, en un intento de generalización, permanece oculta a los lectores. El propio Walpole, en su Prólogo a la primera edición de la obra, precisa que:

Si el relato se escribió en las fechas en que se supone que ocurrió, debió de ser entre 1095, la época de la primera Cruzada, y 1243, la fecha de la última, o no mucho después. No hay otras referencias en la obra que nos permitan adivinar el período en que transcurre el relato (Walpole, 1982: 15).

No sucede lo mismo, sin embargo, en Los misterios de Udolfo, donde, desde las primeras líneas, se emplaza la narración de los hechos en una fecha concreta, 1584. 
El empleo del tiempo interno, por su parte, adolece de alguna de las propiedades de las primitivas novelas griegas, de la misma manera que lo hiciera en el dibujo de los personajes y en la disposición del argumento. El tiempo durante el cual se desarrollan las múltiples y diversas aventuras de sus protagonistas no es medido ni calculado en la novela, «son simplemente días, noches, horas, momentos, medidos solo técnicamente en los límites de cada una de las aventuras» (Bajtín, 1989: 243). Sin embargo y a pesar de que la novela gótica está construida sobre la base del tiempo de la aventura de tipo griego, no es imprescindible que todos sus componentes se manifiesten para crear este efecto; basta con que «un cierto elemento de ese tiempo se implique en otras series temporales para que aparezcan inevitablemente los fenómenos que los acompañan» (Bajtín, 1989: 249).

Sin embargo y coherentemente con lo expuesto, la novela gótica, en un paso más en la delimitación del cronotopo, rompe con la continuidad de la coordenada temporal ${ }^{23}$, del mismo modo que lo hacía con la espacial, al presentarnos una serie de tiempos internos inconexos entre sí, en palpable oposición a los textos promovidos por el Iluminismo. Aparece el «hiperbolismo fantástico del tiempo» (Bajtín, 1989: 306). El tiempo interno se complica; no es presentado de forma lineal y, en ocasiones, llega a ser, incluso, contradictorio porque:

[...] se invoca con tal fuerza la tiranía del pasado (maldiciones familiares, supervivencia de despotismo y superstición) que se acaba por reprimir las esperanzas del presente [...] y haciendo estallar la dimensión temporal en que se inscribe, afirma un presente inmóvil: el tiempo se paraliza, se anula, se abstrae, se hace espacio cerrado (Molina Foix, 2003: 18).

La losa del pasado, que determina y estructura el relato, pone de relieve la recuperación del castillo no sólo como elemento espacial, sino, y de acuerdo con la teoría de Bajtín, como componente primordial que influye en el elemento espacial. No debemos olvidar, por ello, que el castillo, protagonista indiscutible de estas novelas, aparece siempre «impregnado de tiempo, de tiempo histórico en el sentido estricto de la palabra, es decir de tiempo del pasado histórico» (Bajtín, 1989: 396). El castillo remite a otra época, a otras generaciones, pero también a leyendas, a tradiciones, a acontecimientos pasados que reviven cada rincón de este y de sus alrededores.

${ }^{23}$ En general puede afirmarse que la conciencia del tiempo no se da en el conjunto de la literatura hasta el siglo XVIII. 
Este complejo uso del tiempo interno se debe, del mismo modo, a que en la caracterización de la novela gótica adquiere especial relevancia lo que Garrido Domínguez denomina tiempo psicológico. Señala este teórico que «la vivencia del tiempo varía de un individuo a otro según su estado de ánimo o según sea la huella que determinados hechos han dejado en su memoria. [...] De acuerdo con ellos, el tiempo se expande o se concentra, adquiere espesor o se diluye» (Garrido Domínguez, 1996: 158). Los personajes que recorren estas novelas no tendrán la misma percepción del tiempo, según el grado de cercanía que presenten con respecto al acontecimiento tenebroso o sobrenatural. Las vivencias de la heroína, protagonista y testigo directo de todos estos sucesos, desbordarán holgadamente los límites del tiempo convencional, al sentir el peso de unos minutos que su angustioso miedo ha convertido en eternos; circunstancia esta que apreciamos en el caso de Emily, quien en los minutos siguientes a una espeluznante visión, siente que «las horas no han pasado». El tiempo, finalmente, no tiene por qué ser único, porque, de hecho, no es idéntico para todos.

También los sueños premonitorios y las sucesivas apariciones espectrales pueden provocar distorsiones en el empleo del tiempo narrativo (Ramos Gómez, 1988: 150). Vemos cómo el futuro puede intervenir en el presente o cómo el pasado puede hacerse más fuerte y real que el propio presente vivido, imponiéndose a este. La aparición en El Monje de la Monja Ensangrentada, por ejemplo, supone una profunda modificación del eje temporal. De hecho, por naturaleza, la aparición de todo fantasma implica, ya de por sí, la interferencia del pasado en el presente. Esta visita cada noche a Ramón de las Cisternas diciendo lo mismo y haciendo lo mismo que la noche precedente y la que seguirá. El tiempo queda suspendido («hasta entonces todas las facultades de mi cuerpo habían estado en suspenso», Lewis, 2003: 266, afirma aterrorizado el personaje) en un eterno presente que vuelve sobre sí mismo, permitiendo encuentros insospechados entre los que murieron antaño y los que aún habitan en la tierra de los vivos, contribuyendo a la sensación de obsesión que padecen los protagonistas y, por ende, los lectores.

No tomar en consideración esta especial percepción del tiempo es condenarse a no encontrar una explicación satisfactoria y coherente para muchas de las aparentes anomalías que se encuentran en las páginas de los relatos góticos. Solo entendido de esta manera podemos comprender que el tiempo quede, en ocasiones, suspendido, dé saltos, se alterne o se prolongue mucho más allá de los límites que se cree posible, convirtiéndose, a veces, en protagonista, en verdadero artífice y causante de la trasgresión. 
Podríamos afirmar, para concluir, retomando el hilo de nuestra argumentación primera, que estamos de acuerdo con Mijail Bajtín en que nos encontramos ante dos motivos más que evidentes a la hora de individualizar este subgénero que recibe el nombre de novela gótica; sin embargo, las coordenadas espacio-temporales que aparecen en este tipo de obras nos determinan un universo mucho más complejo y que no admite ser reducido a límites tan restringidos. Entendemos entonces que, manteniendo este planteamiento teórico, la novela gótica, precisa, todavía, de un estudio más detenido y complejo, pues incluso esas mismas magnitudes nos sitúan ante un mundo literario harto complicado. Recuperamos, eso sí, la valía de su legado, por considerar que el mismo supone una suerte de patrimonio que recogerá la narrativa romántica posterior, y que, más allá de la conjunción de un castillo y un pasado, nos hallamos ante un cronotopo lleno de matices que influirá sobre la narrativa romántica posterior o incluso, nos atreveríamos a declarar, sobre el conjunto de la literatura.

\section{REFERENCIAS BIBLIOGRÁFICAS}

ÁLVAREZ MÉNDEZ, N. (2002). Espacios narrativos. León: Universidad de León / Secretariado de Publicaciones y Medios Audiovisuales.

- (2003). «Hacia una teoría del signo espacial en la ficción narrativa contemporánea». Signa. Revista de la Asociación Española de Semiótica 12, 549-570.

AMICOLA, J. (2003). La batalla de los géneros: novela gótica versus novela de educación. Rosario: Beatriz Viterbo Editora.

BACHELARD, G. (1993). El aire y los sueños. México: Fondo de Cultura Económica.

BAJTÍN, M. (1989). Teoría y estética de la novela. Madrid: Taurus.

BARELLA, J. (1994). «La literatura fantástica en España». Anthropos 154155 (marzo-abril), 11-20.

BOBES NAVES, M. ${ }^{a}$ C. (1985). Teoría general de la novela. Semiología de «La Regenta». Madrid: Gredos.

BURKE, E. (2005). Indagación filosófica sobre el origen de nuestras ideas acerca de lo sublime y lo bello. Madrid: Alianza Editorial.

CLERY, E. J. y MILES, R. (2000). Gothic Documents. A Sourcebook. 17001820. Manchester and New York: Manchester University Press. 
DEVER, A. (2007). «La novela gótica y paralelos en Nada de Carmen Laforet». The South Carolina Modern Language Review 6.1, 59-75.

ESTEBÁNEZ CALDERÓN, D. (1999). Diccionario de términos literarios. Madrid: Alianza Editorial (Colección Filología y Lingüística).

FERRERAS, J. I. (1973). «La novela de terror». Capítulo IX de Los orígenes de la novela decimonónica (1800-1830). Madrid: Taurus.

GARRIDO DOMÍNGUEZ, A. (1996). El texto narrativo. Madrid: Editorial Síntesis.

KANT, E. (1984). Lo bello y lo sublime: ensayo moral y estético. Madrid: Austral.

KRISTEVA, J. (1980). Pouvoirs de l'horreur: essais sur l'objection. París: Fayard.

LEVY, M. (1968). Le roman gothique anglais. Toulouse: Faculté de Lettres de Toulouse.

LEWIS, M. G. (1796). The Monk. Traducción de V. Molina Foix. (2003). El Monje. Madrid: Cátedra.

LOVECRAFT, H. Ph. (1984). El horror en la literatura. Madrid: Alianza.

MORALES, A. M. (2004). «Transgresiones y legalidades (lo fantástico en el umbral)». En Odiseas de lo fantástico, 25-37 México: CILF.

NEGRONI, M. (1999). Museo Negro. Buenos Aires: Grupo Editorial Norma.

RADCLIFFE, A. (1794). The Mysteries of Udopho. Traducción de C. J. Costas Solano (2003). Los misterios de Udolfo. Madrid: Valdemar.

RAMOS GÓMEZ, M. T. (1988). Ficción y fascinación: literatura fantástica prerromántica francesa. Valladolid: Universidad.

VILLANUEVA, D. (1989). El comentario de textos narrativos: La novela. Gijón / Madrid: Júcar.

WALPOLE, H. (1764). The Castle of Otranto. Traducción de M. Praz (1982). El castillo de Otranto. Barcelona: Bruguera. 